Veteriner Farmakoloji ve Toksikoloji Derneği Bülteni

Bulletin of Veterinary Pharmacology and Toxicology Association

e-ISSN 2667-8381, 11 (2): 49-60, 2020

DOI: $10.38137 /$ vetfarmatoksbulten.768811

\title{
COVID-19 VE HAYVANLAR
}

\author{
Ahmet Kürşat AZKUR \\ Kırıkkale Üniversitesi Veteriner Fakültesi, Viroloji Anabilim Dalı, Kırıkkale
}

ORCID: 0000-0002-5597-8917

*Sorumlu Yazar: Ahmet Kürşat AZKUR

Geliş Tarihi: 13.07 .2020

E-Posta: azkurkursat@hotmail.com

Kabul Tarihi: 29.07.2020

\section{ÖZET}

Koronavirüsler insanlarda ve hayvanlarda birçok enfeksiyona yol açmaktadır. Koronavirüsler içerisinde 31 Aralık 2019 tarihinde Çin Halk Cumhuriyeti'nde başlayan salgının nedeni olan SARS-CoV-2 bu ailenin en dikkat çeken üyesi olarak ortaya çıkmıştır. Virüsün insanları ve hayvanları enfekte ettiği rapor edilmiştir. Bu derlemede, SARS-CoV-2 enfeksiyonlarının hayvanlardaki rolü ve hayvanlarda bu virüsle yapılan önemli çalışmaların özetlenmesi amaçlanmıştır. SARS-CoV-2 enfekte kedi, gelincik, vizon ve makak gibi hayvanların COVID-19 benzeri semptomlar ile hastalık geliştirdikleri ve virüsün çevreye saçılmasında önemli rol oynadıkları görülmüştür. Enfekte hayvanlar, insandakine benzer hastalık tablosu geliştirmelerinden dolayı, deneysel olarak, COVID-19 hastalığının tedavisi, immünolojisi, koruma ve kontrol çalışmalarında da kullanılmışlardır. Gelecekte COVID-19 hastalığı ile ilgili hayvanlardan elde edilen veriler de hastalığın yol açtığı sorunların çözülmesinde önemli rol oynayacaktır.

Anahtar Kelimeler: Koronavirüs, SARS-CoV-2, Hayvanlar.

\section{COVID-19 AND ANIMALS}

\begin{abstract}
Coronaviruses cause many infections in humans and animals. The SARS-CoV-2 virus, which began in the People's Republic of China on December 31, 2019, has emerged as the most remarkable member of this family. It is reported that the virus can infect humans and animals. It is aimed to show the role of SARS-CoV-2 infections in animals and to summarize the important studies of this virus in animals in the review. Cats, ferrets, mink, macaque infected with SARS-CoV-2 develop disease with symptoms similar to COVID-19 and play an important role in spreading the virus to the environment. They have also been used experimentally in the treatment, immunology, protection and control studies of COVID-19 disease because animals are mimics disease model. In future data derived from these animals will play a crucial role in resolving the problems caused by COVID- 19 .
\end{abstract}

Keywords: Coronavirus, SARS-CoV-2, Animals. 


\section{GíRIŞ}

İnsan ve hayvanları ortak enfekte eden mikroorganizmalar zoonozlar olarak ifade edilmektedir. Zoonoz; omurgalı hayvanlardan insanlara (zooantroponoz) ve insanlardan omurgalı hayvanlara geçen (antropozoonoz) herhangi bir enfeksiyon hastalığını tanımlayan terimdir. Dünya üzerinde yaklaşık 6.400 memeli türü tanımlanmıştır. $\mathrm{Bu}$ memelilerin oluşturduğu en büyük takımlar; kemirgenler, yarasalar ve eulipotyphlar [kirpi, köstebek, fare (shrew) ve diğerleri], primatlar (insanlar, maymunlar ve diğerleri), cetartiodactylar (deniz memelileri ve çift toynaklılar) ve carnivorlar (kediler, köpekler, fok ve diğerleri) diye adlandırılmaktadır. Bir çalışmada, 142 zoonotik virüs enfeksiyonu ile konak arasındaki ilişsi değerlendirilmiştir. Bu çalışmada karada yaşayan 5335 vahşi memeli türünden 609'unun $(\% 11,4)$ en az bir zoonotik virüs taşıdığı ve 609 memeli türünün 354 'ü $(\% 58,1)$ sadece bir zoonotik virüse konaklık yapmakta olduğu bildirilmiştir. İnsanlarda hastalığa neden olan 1415 enfeksiyöz ajandan 868'i (\%61) zoonozdur ve bunların önemli bir kısmını virüsler oluşturmaktadır. Zoonotik virüslere; rodentiakemirgenler \%61, chiroptera-yarasalar \%30, primatlar- $\% 23$, artiodactyla-çift toynaklılar $\% 21$, carnivora-etoburlar \%18 ve diğer türler ise daha az oranda konaklık etmektedir. Aynı çalışmada üç memeli türünün (kemirgenler, yarasalar ve primatlar) bugüne kadar saptanan zoonotik virüslerin çoğu için $(\% 75,8)$ konaklık yaptığı ve bu türlerin tüm karasal memeli türlerinin \%72,7'sini temsil ettiğini ve karasal memeli türlerinin çoğunda $(\% 88,6)$, henüz zoonotik bir virüsle enfeksiyon rapor edilmediği beyan edilmiştir (Johnson ve ark., 2020). Başka bir çalışmada ise, yapılan metagenomik analizde, okyanustan toplanan örneklerin henüz kefedilmemiş 195,728 viral popülasyon içerdiği bildirildi (Gregory ve ark., 2019). Bu veriler ise gelecekte daha çok viral zoonotik etkenin ortaya çıkma potansiyelini açıkça ortaya koymaktadır.

31 Aralık 2019'da Dünya Sağlık Teşkilatı (World Health Organization-WHO) Çin Ülke Ofisi, Çin Halk Cumhuriyeti'nin Hubei Eyaleti'nin Vuhan şehrinde tespit edilen ve etiyolojisi bilinmeyen pnömoni vakalarının olduğunu duyurdu. $\mathrm{Bu}$ vakaların sorumlusu yeni bir koronavirüs (2019nCoV), 7 Ocak'ta Çinli yetkililer tarafindan hastalık etkeni olarak tanımlandı. Çin'in yeni koronavirüse $(\mathrm{nCoV})$ ait paylaştığı genetik sekans, daha fazla ülkenin hastaları hızlı bir şekilde teşhis etmesini sağladı (Azkur, 2020a, 2020b; Azkur ve ark., 2020). Başlangıçta, yeni tip koronavirüsün deniz ürünleri marketinde bulunan hayvanlardan insanlara geçtiği düşünüldü. Yeni tip koronavirüsün sekans analizi paylaşıldığında virüsün yarasalarda enfeksiyon yapan koronavirüs ve SARS-CoV (Severe Acute Respiratory Syndrome-Coronavirus) ile yüksek oranda benzerlik gösterse de, COVID-19'un yayılımında (arakonak) veya kökeninde hangi hayvanların rol oynadığı henüz netlik kazanmamıştır (Azkur, 2020a; Azkur ve ark., 2020; Riggioni ve ark., 2020).

Koronavirüsler, 26-32 kilobaz arasında değişen pozitif anlamlı tek sarmallı viral RNA genomuna sahip, yaklaşık $100 \mathrm{~nm}$ çapında zarflı virüslerdir. Koronavirüsler (CoV'ler) insan ve omurgalılar için önemli bir patojendir. Coronaviridae ailesinin Orthocoronavirinae alt ailesinde, alfakoronavirüsler, betakoronovirüsler, deltakoronovirüsler, gamakoronovirüsler ve olmak üzere 4 ayrı genusu (cins) bulunmaktadır. Alfakoronavirüsler; insan, yarasa, domuz, kedi ve köpekleri enfekte eden 17 ayrı virüs türünü içermektedir. Deltakoronavirüsler; yaban ördeği, bülbül, gece balıkçıll, saz tavuğu ve ispinoz gibi kuş 
türlerini enfekte eden toplam 7 virüs türünü içerir. Gamakoronavirüsler; kanatlılar ve balinayı enfekte eden 2 ayrı virüs türünü barındırır ve tavuklarda infeksiyöz bronşitise neden olan bir enfeksiyon burada yer almaktadır. SARS-CoV-2 betakoronavirüsler genusu altında yeni bir virüs olarak tanımlanmıştır. Son yirmi yılda 2002'de SARS-CoV, 2012'de MERS-CoV ve 2019'da SARS-CoV-2 salgını ortaya çıktı. MERS'in tek hörgüçlü develerden insanlara, SARS'ın ise misk kedileri veya yarasadan insanlara geçtiği bildirilmiştir (Cheng ve ark., 2007; Azkur, 2020b, 2020a; Azkur ve ark., 2020)

Hayvanlar deneysel enfeksiyonları, hayvan sağlığı ve refahı, vahşi yaşamı koruma ve biyomedikal araştırmalar için kullanılmaktadır. Böylece hastalıkların patolojisi, epidemiyolojik çalışmalar, aşı ve antiviral ilaçların geliştirilmesi için deneysel olarak enfekte edilmiş ve bu amaç altında insanlığa hizmet etmektedirler. COVID-19'un yeni bir virüs olması dolayısı ile hakkında merak edilen birçok soru vardır. Her bir çalışma saatinde yaklaşık 10 makale yayımlanarak bu soruların birçoğuna cevap verilmiştir. Fakat halen cevap bekleyen birçok soru vardır ("Questions and answers on covid-19", 2020; Bonini ve Maltese, 2020; Riggioni ve ark., 2020). Bu sorulardan bir tanesi, hastalığın evcil ve vahşi hayvanlardaki seyrinin nasıl geliştiği veya virüsün hayvanlardan insanlara bulaşıp bulaşmadığ1 konusudur. Bu derleme ile SARS-CoV-2 virüsü ile hayvanlarda yapılan çalışmalar ve gözlemlerin kısaca özetlenmesi amaçlanmıştır.

Birçok araştırma ile; SARS- CoV-2 S (SpikeÇıkıntı) proteinin; insan (Homo sapiens), gelincik türleri (Mustela erminea, Mustela putorius furo), makak (Macaca mulatta), maymun (Rhinopithecus roxellana), orangutan (Pongo abelii), şempaze (Pan troglodytes), babun (Papio Anubis), misk kedisi
(Paguma larvata), yarasalar (Rhinolophus macrotisRhinolophus sinicus- Rousettus leschenaultiiRhinolophus pearsonii- Pteropus vampyrus), domuz (Sus scrofa- Sus scrofa domesticus), köpek (Canis lupus familiaris), kedi (Felis catus), pangolin (Manis javanica), at (Equus caballus), sığır (Bos taurus), koyun (Ovis aries), tavşan (Oryctolagus cuniculus), tilki (Vulpes vulpes), hamster (Phodopus campbelliCricetulus griseus- Mesocricetus auratus), sincap (squirrel) ACE2 reseptörlerine bağlanma olasılığ olduğu, tahmini modelleme ile gösterildi (Hernandez ve ark., 2020; Luan ve ark., 2020; Zhai ve ark., 2020). SARS-CoV-2'nin hala tam olarak hangi hayvanları enfekte edip etmediği ve SARSCoV-2'nin yayılmasında hayvanların nasıl bir rol oynadığı bir cevaplanmamış ve epidemiyolojik açıdanda önemli bir sorudur. Hayvanlardaki ACE2 reseptörüne, SARS-CoV-2 $\mathrm{S}$ proteininin bağlanması, virüs enfeksiyonun başlaması için önemli bir adımdır. Bu bağlanmanın belirlenmesi, muhtemel konakların tespitinde önemli rol oynayacaktır.

\section{Yarasa}

Yapılan tam genom sekans analizlerinde, SARSCoV-2 virüsünün \%91,02 oranında Pangolin-CoV, $\% 90$ oranında ise BatCoV RaTG13 ile benzerlik gösterdiği belirlenmiştir (SARS-CoV-2 reference genome (GenBank:MN908947) (Azkur, 2020b; Zhang ve ark., 2020). Yarasalar ve koronavirüsler ile ilgili çok sayıda çalışma yapıldığı görülmektedir. Yapılan çalışmalarda yarasaların barındırdığ koronavirüslerin insanlar için potansiyel bir tehlike olduğu, hatta bunun ne zaman patlayacağ 1 tam olarak bilinmeyen bir saatli bombaya benzediği yıllar önce bildirilmiştir (Cheng ve ark., 2007; Menachery ve ark., 2017). Çin Halk Cumhuriyeti'nde ki bir yarasa türünde bulunan (Chinese horseshoe bat-Çin 
nalburunlu yarasa) SARS-benzeri WIV1-CoV'ünün SARS-CoV gibi ACE2 reseptörlerine bağlanma potansiyelinin olduğu rapor edilmiştir (Menachery ve ark., 2016). Başka bir çalışmada ise laboratuvarda sentetik olarak yaratılan ve gen maniplasyonları (reverze genetik) kullanılarak yapılan SARS benzeri koronavirüslerin fareleri ve insanların silyalı hava yolu hücrelerini (human ciliated airway epithelial cells.) enfekte ettiği gösterilmiştir (Becker ve ark., 2008). PRJNA260063 giriş numarası olan proje ile alfa ve beta koronavirüslerin insan ve diğer memeli hücrelerine adaptasyon çalışmaları da başarı ile tanımlanmıştır. Yine başka bir çalışmada SARSbenzeri bir virüs olan SHC014- CoV'un Çin nalburunlu yarasaları enfekte ettiği ve onlarda doğal olarak bulunduğu bildirilmiştir. Tersine genetik kullanılarak SHC014 virüsünün spike S proteini ile yaratılan yeni virüsün insan ACE2 reseptörlerine bağlanma yeteneğinin kazandırıla bildiği gösterilmiştir. Aynı zamanda yaratılan bu rekombinant virüsün hem insan akciğer hücrelerine tutunabildiği in vitro olarak hem de fareleri enfekte etme potansiyeli in vivo olarak gösterilmiştir (Menachery ve ark., 2015). Bununla beraber şu an dünyada yeni bir pandemiye neden olan bu virüsün, doğal şartlarda geliştiğini gösteren önemli bir makale yayımlanmıştır (Andersen ve ark., 2020).

\section{Kedi-Köpek}

Hong Kong'da yaşayan 60 yaşında bir kadının 12 Şubat 2020 tarihinde COVID-19 semptomları göstermeye başladığı ve 24 Şubat tarihinde bu rahatsızlığı ile ilgili olarak hastaneye başvurduğu bildirilmiştir. $\mathrm{Bu}$ bayan, 8 Mart 2020 tarihinde iyileşerek evine geri gelmiştir. Bu arada hastanın evinde bulunan, 17 yaşında Pomeranian Loulou cinsi köpekten, 26-28 Şubat ve 2 Mart 2020 tarihlerinde örnek alınarak qRT-PCR ile SARS-CoV-2 yönünden araştırılmıştır. Araştırmalar sonucunda SARS-CoV-2 pozitiflik tespit edilen köpek, maalesef 16 Mart 2020 tarihinde hayatını kaybetmiştir. İkinci vaka ise yine Hong Kong'da bulunan bir Alman çoban köpeğinde tespit edilmiştir (Leroy ve ark., 2020). Bu köpeklerden alınan nasal örneklerden SARS-CoV-2 virüsünün tüm gen sekans elde edilmiş ve filogenetik analizi yapılmıştır (GenBank Accession numbers; MT215193, MT215194, MT215195, MT270814, MT270815 and MT276600) (Sit ve ark., 2020). Hollanda da sahibi COVID-19 olan bir köpekte SARS-CoV-2 tespit edilmiştir (Hossain ve ark., 2020).

Kedilerin; SARS-CoV ile enfekte olabildiği, SARS-CoV enfeksiyonu nedeniyle ölen insanlardakine benzer şekilde aktif enfeksiyon geliştirdikleri, aynı şekilde virüsü saçtıkları, akciğerinde benzer lezyonların geliştiği gösterilmiştir. 2003 yılında yayımlanan bir çalışmada Hong Kong'da 100 kişinin SARS-CoV enfeksiyonu geçirdiği bir apartmanda yaşayan evcil kedilerde RT-PCR testi pozitif sonuç vermiştir. Kedilerin SARS-CoV-2 enfeksiyonuna duyarlı olduğu ve hastalığı taşıdıkları rapor edilmiştir (Halfmann ve ark., 2020). Çin Halk Cumhuriyeti'nin Vuhan şehrinde seroprevalans çalş̧masında, 102 evcil kedinin 15'ninde SARS-CoV-2 virüsüne karş1 antikor varlığ ELISA ve nötralizayon testi ile tespit edilmiştir (Abdel-Moneim ve Abdelwhab, 2020; Zhang, 2020). 24 Mart 2020 tarihinde Amerika Birleşik Devletleri'nin Nevyork şehrinde, 4 yaşındaki kısa tüylü erkek bir kedinin gözyaşı akıntısı, hırıltı ve kısmi uyuşukluk ile karakterize solunum hastalığ1 geliştirdiği görülmüştür. Kedinin ağırlık kaybettiği ve $38.6^{\circ} \mathrm{C}$ vücut isısına sahip olduğu belirlenmiştir. Kedi Mycoplasma felis, Bordetella bronchiseptica, feline calicivirus, Chlamydophila felis, feline herpesvirus, ve influenza 
A H1N1 gibi kedilerde solunum enfeksiyonuna yol açan etkenler yönünden incelenmiş ve yapılan testler negatif olarak görülmüştür. Fakat SARS-CoV-2 qRT-PCR pozitiflik saptanmıştır. 1 Nisan 2020 tarihinde Nevyork şehrinde 5 yaşlı dişi Devon Rex kedisinde aynı şekilde SARS-CoV-2 tespit edilmiştir. İki kedinin de sahiplerinin COVID-19 olduğu rapor edilmiştir (Newman ve ark., 2020). 31 Mart 2020 tarihinde Hong Kong'da COVID-19 hastasının evinde bulunan bir kediden alınan ağız, burun ve rektal sivap örneklerinde, SARS-CoV-2 RNA'sı belirlenmiş fakat kedide herhangi bir klinik belirti görülmemiştir. İtalya seyahat geçmişine sahip Belçikalı COVID-19 hastasının evinde bulunan, kusma, ateş iştahsızlık ve bitkinlik gibi klinik belirtileri olan kedide yüksek seviyede SARS-CoV2 RNA'sı tespit edilmiştir (Hossain ve ark., 2020). Amerika Birleşik Devletleri'nde evcil kediler gibi hayvanat bahçesinde bulunan bazı kaplanlarda da SARS-CoV-2 tespit edilmiştir (Cleary ve ark., 2020). Biyogüvenlik seviyesi 4 ve hayvan biyogüvenlik seviyesi 4 olan laboratuvarlara sahip Çin Halk Cumhuriyetine bağlı Harbin Veteriner Araştırma Enstitüsünde deneysel olarak $10^{5}$ plaqueforming unit (PFU) SARS-CoV-2 intranazal olarak 6-9 aylık 7 adet kediye verilmiştir. Bu çalışmada, 3 sağlıklı kedi ise, bu enfekte kedilerden uzak bir izolatörde kafesler arasında $4 \mathrm{~cm}$ birakılarak tutulmuştur. İntranazal enfekte kedilerin COVID-19 semptomları geliştirdiği, klinik ve postmortem gözlemler sonucuda teyit edilmiştir. Shi ve arkadaşları ilaveten izolatörde tutulan 3 sağlıklı kedinin ise SARS-CoV-2 enfekte kedilerden saçılan virüs ile enfekte olduğu tespit ettiler. Köpeklerin ise kediler kadar enfeksiyona duyarlı olmadığı rapor edilmiştir (Shi ve ark., 2020).

\section{Gelincik}

SARS enfeksiyonuna gelinciklerin duyarlı olduğu yapılan çalışmalar ile gösterilmiştir (Zamoto ve ark., 2006; Dong ve ark., 2007). Bu duyarlıkları ve maymunlara göre daha maniplasyonu kolay ve daha ekonomik bir model olmaları nedeni ile, SARS'a karşı deneysel enfeksiyon ve aşı çalışmalarında da tercih edilmişlerdir (Darnell ve ark., 2007; Kobinger ve ark., 2007; See ve ark., 2008). Gelincikler $10^{3}$ doku kültürü enfektif doz $50\left(\right.$ DKID $\left._{50}\right)$ ile intranasal olarak enfekte edildiklerinde, vücut ısılarında artış (enfeksiyon sonrası 2-6 günler), lenfosit sayısında azalma gibi belirtileri göstermişlerdir (Chu ve ark., 2008). İlaveten SARS-CoV replikasyonu ve akciğer patolojisi insana benzediği için, gelincikler önemli bir model olarak kabul görmüşlerdir (Ruh, 2010).

Deneysel olarak gelinciklerin SARS-CoV-2 enfeksiyonuna duyarlı olup olmadığı göstermek için çalışmalar yapılmıştır. Bu çalışmalardan Güney Kore Chungbuk Ulusal Üniversitesinde gerçekleştirilen çalışmada, influenza A, MERS$\mathrm{CoV}$, ve SARS-CoV yönünden antikor negatif olarak tespit edilen gelincikler biyogüvenlik seviyesi 3 laboratuvarlarda bulunan izolatörler içerisinde enfekte edilmişlerdir. Enfeksiyon $10^{5,5}$ DKID $_{50}$ intranazal yol ile yapılmış ve enfekte gelinciklerin ağırlık kayıpları, vücut ısılarındaki değişiklikler ve viral yükleri, dokularında meydana gelen değişimler kayıt altına alınmıştır. Enfekte gelinciklerin vücut ısılarında artış, enfeksiyon sonrası 2 ve 12. günler arasında gözlenmiştir. Virüs burun, trakea, akciğer, böbrek ve bağırsakta enfeksiyon sonrası 2 ve 12 . günler arasında tespit edilmiştir. Burun bölgesinin en yüksek viral yüke sahip olduğu görülmüştür. SARSCoV-2 virüsünün nazal akıntılar, tükrük, idrar ve dışkı ile yayıldığı, gelinciklerin birbirlerini enfekte 
ettiği ve etkenin gelinciklerde akut bronşiyolit (acute bronchiolitis) yol açtı̆̆ gösterilmiştir (Kim ve ark., 2020). Çin Halk Cumhuriyeti'nde yapılan başka bir çalışmada gelinciklerin kediler kadar enfeksiyona duyarlı olduğu rapor edilmiştir (Shi ve ark., 2020). Bu çalışmalar temel alınarak SARS-CoV-2'ye karşı geliştirilen antiviral ilaçların in vitro etkinleri çalışmaları ve immünopatolojik deneysel modeli üzerinde çalışılmış ve önemli ipuçları elde edilmiştir (Blanco-Melo ve ark., 2020; Park ve ark., 2020).

\section{Golden Syrian Hamster}

ACE2 ve SARS-CoV-2 S proteinlerinin birbirlerine uyumunu gösteren çalışmalarda, golden syrian hamsterlarının (Mesocricetus auratus) enfeksiyona duyarlı olabileceği düşünülmüştür. Hong Kong'da bulunan BSL-3 laboratuvarında yapılan çalışmada 610 haftalık golden syrian hamsterları $10^{5} \mathrm{PFU}$ (plaque-forming unit) SARS-CoV-2 ile intranazal olarak enfekte edilmiştir. Enfeksiyon sonrası syrian hamsterlarında viral yük, kemokin sitokin profili, histopatlojik değişiklikler gözlenmiştir. Enfekte hayvanlarda \%11'leri bulan ağırlık kaybı enfeksiyon sonrası 1. ve 6. günlerde gözlenmiş fakat 14 . gün hayvanlar tekrar kaybettikleri kiloları almışlardır. Enkekte hamsterların uyuşukluk, karışık tüyler, kambur sırt duruşu ve hızlı nefes alma gibi klinik belirtiler gösterdiği görülmüştür. Hayvanların burun, akciğer dokularında virüs tespit edilirken ve yakın temas ile birbirlerini enfekte edebildikleri gözlenmiştir (Chan ve ark., 2020b). İlginç bir şekilde; yakın temas ile birbirlerini enfekte edebilen Syrian hamsterlarının, cerrahi maskenin bir bölümü kullanılarak (Surgical mask partition) damlacık yolu ve/veya havadaki damlacıkların neden olduğu (airborne droplet nuclei) enfeksiyonundan korunduğu gösterilmiştir (Chan ve ark., 2020a).

\section{Vizon-Mink}

Vizonlar etçil (balık, küçük rodentler, kabuklular, böcekler), sansargillerden bir tür yarı sucul, gelincik türüdür. Hollanda ve Danimarka'da kürkü, kozmetik sanayinde kullanılan yağ 1 ve belirli krem türlerinin üretimi için yoğun bir şekilde yetiştirilmektedir. SARS-CoV'ünün vizon epiteliyal hücreleri (Mink lung epithelial cells (Mv 1 Lu) ve R-Mix) enfekte ettiği bildirilmiştir. Özellikle bu hücre hatlarından Mv1Lu'nun SARS-CoV için permisif karakterde olduğu, daha güvenli tanı tekniklerinin geliştirilmesi, virüsün yaşam siklusunun daha iyi anlaşllabilmesi ve rezervuar hayvanların belirlenmesi için iyi bir model olarak kullanılabileceği rapor edilmiştir (Gillim-Ross ve ark., 2004). Fakat Mv $1 \mathrm{Lu}$ hücrelerinde Vero hücrelerinin aksine SARS-CoV'nün litik olmayan enfeksiyonlara yol açttğı görülmüştür (Mossel ve ark., 2005). Hollanda'da ilk kez 26 Nisan 2020 tarihinde iki vizon çiftliğinde SARS-CoV-2 tespit edilmiştir. $\mathrm{Bu}$ çiftliklerde toplam 21200 adet vizonun bulunduğu bildirilmiştir. $\mathrm{Bu}$ vizonların intersiyel pnömoni ve konjesyon, akciğer ödemi ve sepsisten hayatlarını kayıp ettiği belirlenmiştir. Yeni nesil sekanslama dizilim analizi ile virüs teyit edilmiş ve gen bankasına sekanslar yüklenmiştir (GenBank MT396266 ve MT457390-MT457399). 26 Mayıs 2020 tarihinde Hollanda'da ki dört vizon çiftliği SARS-CoV-2 varlığı RT-PCR ile araştırıldığında, vizonların, solunum problemleri de dahil olmak üzere çeşitli semptomlar gösterdiği gözlenmiştir. Bazı çalışanlarda koronavirüs semptomları görülmüştür ve bu çalışanlarda COVID-19 hastalı̆̆ı teyit edilmiştir. Vizonların akciğer, boğaz sıvaplarında SARS-CoV-2 saptanmış ve ileri tetkikler neticesinde, vizonların virüsü birbirlerine aktardığı sonucuna varılmıştır 
(Oreshkova ve ark., 2020). Vizonlar arasında hastalığın çok yayıldığı ve bu nedenden dolayı hastalıkla mücadele için, 500000'e yakın vizon öldürdüğü bildirilmiştir (Maron, 2020).

\section{Maymunlar}

İnsan olmayan primatlar içerisinde Cynomolgus macaque (Macaca fascicularis) ve Rhesus macaque (Macaca mulatta) klinik öncesi, akademik ve endüstriyel araştırmalarda kullanılan türler arasında yer almaktadır. Her yıl yaklaşık 100.000'den fazla insan olmayan primat bu amaçlar dâhilinde kullanılmaktadır ve bu rakamlar yaklaşık olarak Amerika Birleşik Devletleri'nde kullanılan deney hayvanlarından \%1'ini teşkil etmektedir (Chatfield, 2017).

SARS-CoV-2'nin, yaşlı maymunlarda (15 yaş), genç maymunlara (3-5 yaş) kıyasla; daha şiddetli interstisyel pnömoniye, şiddetli klinik bulgulara, yüksek viral replikasyona, akciğer grafisinde değişikliklere ve farklı immün yanıta neden olduğu gösterilmiştir (Yu ve ark., 2020b). Başka bir çalışmada, intranazal ve intratrakel (intratracheal) SARS-CoV-2 ile enfekte edilen makakların (cynomolgus macaques) biri hariç genel olarak klinik tablolarında bozukluk olmadığı bildirilmiştir. Nasal sıvap örneklerinde; genç makaklarda (4-5 yaşında) enfeksiyon sonrası 2 . günde, yaşlı makaklarda (15-20 yaşında) 4. günde SARS-CoV-2 RNA miktarı en yüksek seviyeye ulaşmıştır. Hayvanlarda genel olarak enfeksiyon sonrası 8. güne kadar virüs belirlenir iken, bir hayvanda virüs 21. günde de tespit edilmiştir. Hayvanların tam kanında çalışma boyunca virüs tespit edilmez iken enfeksiyon sonrası 4. günde otopsisi yapılan makakların akciğerlerinde konsolidasyon gözlenmiştir. Virüs nazal septum, trakea, bronşlar, akciğer lobları, ilyum, kolon, trekao-bronşiyal epiteller, bronşiyal lavajda tespit edilmiştir. En yüksek miktarda virüs içeren dokular ise başlıca nasal septum ile akciğer lobları olarak belirtilmiştir (Rockx ve ark., 2020).

COVID-19 hastalı̆̆ 1 ile mücadele de kullanılmak üzere hala etkin antiviral ve etkin bir ticari aşı geliştirilememiştir. Dünyada birçok firma ve akademik kuruluş COVID-19 hastalığına karş1 etkin aşı geliştirmenin birçok önemli aşamasını geçtiler. Aşı geliştirmede başlıca iki aşama vardır. Bunlar klinik öncesi aşama ve klinik (insan klinik deneyleri) aşaması olarak adlandırılmaktadır. 12 Temmuz 2020 tarihi itibari ile 21 adet aşı adayı klinik insan deneyleri aşamasında iken, 139 adet aşı adayı ise klinik öncesi aşamalarda yer almaktadır. Ülkemizden herhangi bir grup henüz bu zamana kadar belirtilen sisteme kayıt yaptırmamıştır. Klinik çalışmaları sürdüren Sinovac firması faz ile Oxford Üniversitesi / AstraZeneca ortaklığı faz 3 aşamasında yer almaktadır. Sinovac firması inaktif aşı üretmek için klinik öncesi çalışmaların son basamağında rhesus makaklarını (rhesus macaques-Macaca mulatta) kulland. Burada makaklar 0, 7. ve 14 . günlerde üç kez kas içi orta doz (3 $\mu \mathrm{g}$ per dose) veya (6 $\mu \mathrm{g}$ per dose) ile aşılandılar ve aşılama sonrası 2 haftada aşılanmış hayvanların serumlarında nötralize edici antikor titresin de artış gözlenmiştir. İlginç bir şekilde araştırmacılar, orta doz ile aşılanan makakların yükssek doz ile aşılanan makaklara göre daha yüksek seviyede antikor ürettikleri tespit etmişlerdir. Çelinç (Challenge) için makaklar $10^{6}$ TCID $_{50}$ SARS-CoV-2 ile intratrakel olarak enfekte edilmiştir. Aşılı hayvanların klinik belirti göstermediği ve daha az oranda virüs saçtığ gözlemlenmiştir (Gao ve ark., 2020). SARS-CoV-2 $\mathrm{S}$ geni ile geliştirilen DNA aşısında ise, rhesus makakları kullanılmıştır. DNA aşılarının etkin koruma sağladığı rapor edilmiştir (Yu ve ark., 
2020a). Makaklar ile SARS-CoV-2'nin patogenezi, kullanılan remdesivir, hidroksiklorokin ve yeniden enfekte olan makakaların korunduğuna ilişkin bilimsel veri sağlayan birçok çalışma vardır (Chandrashekar ve ark., 2020; Deng ve ark., 2020; Hachim ve ark., 2020; Le Bras, 2020; Rosenke ve ark., 2020; Shan ve ark., 2020; van Doremalen ve ark., 2020; Williamson ve ark., 2020; Yu ve ark., 2020b).

Sonuç olarak SARS-CoV-2 zoonotik bir enfeksiyondur. Fakat SARS-CoV-2 virüsünün henüz hayvanlardan insanlara geçişi birçok canlı türünde teyit edilememiştir. Fakat Hollonda'da birçok vizon bu hastalık yüzünden epidemiyolojik kaygılardan dolayı itlaf edilmiştir. Hayvanlar insanlara birçok bilimsel çalışmada hayatlarını kaydederek yardım etmektedir. Çalışmalarda kullanılan bu hayvanların, araştırmalar neticesinde çevreyi ve insanı kontamine etmemesi için, ülkemizde hayvan biyogüvenlik seviyesi yüksek laboratuvarlara (Animal Biosafety Levels) ihtiyaç duyulmaktadır. Zoonozlarla ve insan aşı çalışmalarının ülkemizde bağımsız olarak yapılabilmesi için, primat merkezini de bünyesinde barındıran, yüksek güvenlik seviyesine sahip laboratuvarları içeren laboratuvarların kurulması ve bu birimlerde çalışacak yetişmiş insan gücüne ihtiyaç duyulmaktadır.

\section{KAYNAKLAR}

Abdel-Moneim, AS., ve Abdelwhab, EM. (2020). Evidence for sars-cov-2 infection of animal hosts. Pathogens, 9(7).

Andersen, KG., Rambaut, A., Lipkin, WI., Holmes, EC., ve Garry, RF. (2020). The proximal origin of sars-cov-2. Nat Med, 26(4), 450452.

Azkur, AK., Akdis, M., Azkur, D., Sokolowska, M., Van De Veen, W., Bruggen, MC., O'mahony, L., Gao, Y., Nadeau, K., ve Akdis, CA. (2020). Immune response to sars-cov-2 and mechanisms of immunopathological changes in covid-19. Allergy, 75(7), 1564-1581.
Azkur, AK, Aksoy. E. (2020a). Yeni bir koronavirüs:2019-ncov. Anadolu İzlenimleri(130), 12-15.

Azkur, AK, Azkur. D., Aksoy E. (2020b). Yeni bir pandemi; sars-cov-2 virüsünün neden olduğu covid-19 hastalığ1. Anadolu İzlenimleri(131), 8-13.

Becker, MM., Graham, RL., Donaldson, EF., Rockx, B., Sims, AC., Sheahan, T., Pickles, RJ., Corti, D., Johnston, RE., Baric, RS., ve Denison, MR. (2008). Synthetic recombinant bat sars-like coronavirus is infectious in cultured cells and in mice. Proc Natl Acad Sci U S A, 105(50), 19944-19949.

Blanco-Melo, D., Nilsson-Payant, BE., Liu, WC., Uhl, S., Hoagland, D., Moller, R., Jordan, TX., Oishi, K., Panis, M., Sachs, D., Wang, TT., Schwartz, RE., Lim, JK., Albrecht, RA., ve Tenoever, BR. (2020). Imbalanced host response to sars-cov-2 drives development of covid-19. Cell, 181(5), 1036-1045 e1039.

Bonini, S., ve Maltese, G. (2020). Covid-19 clinical trials: Quality matters more than quantity. Allergy.

Chan, JF., Yuan, S., Zhang, AJ., Poon, VK., Chan, CC., Lee, AC., Fan, Z., Li, C., Liang, R., Cao, J., Tang, K., Luo, C., Cheng, VC., Cai, JP., Chu, H., Chan, KH., To, KK., Sridhar, S., ve Yuen, KY. (2020a). Surgical mask partition reduces the risk of non-contact transmission in a golden syrian hamster model for coronavirus disease 2019 (covid-19). Clin Infect Dis.

Chan, JF., Zhang, AJ., Yuan, S., Poon, VK., Chan, CC., Lee, AC., Chan, WM., Fan, Z., Tsoi, HW., Wen, L., Liang, R., Cao, J., Chen, Y., Tang, K., Luo, C., Cai, JP., Kok, KH., Chu, H., Chan, KH., Sridhar, S., Chen, Z., Chen, H., To, KK., ve Yuen, KY. (2020b). Simulation of the clinical and pathological manifestations of coronavirus disease 2019 (covid-19) in golden syrian hamster model: Implications for disease pathogenesis and transmissibility. Clin Infect Dis.

Chandrashekar, A., Liu, J., Martinot, AJ., Mcmahan, K., Mercado, NB., Peter, L., Tostanoski, LH., Yu, J., Maliga, Z., Nekorchuk, M., BusmanSahay, K., Terry, M., Wrijil, LM., Ducat, S., Martinez, DR., Atyeo, C., Fischinger, S., Burke, JS., Slein, MD., Pessaint, L., Van Ry, A., Greenhouse, J., Taylor, T., Blade, K., Cook, A., Finneyfrock, B., Brown, R., Teow, E., Velasco, J., Zahn, R., Wegmann, F., Abbink, P., Bondzie, EA., Dagotto, G.,

Gebre, MS., He, X., Jacob-Dolan, C., Kordana, N., Li, Z., Lifton, MA., 
Mahrokhian, SH., Maxfield, LF., Nityanandam, R., Nkolola, JP., Schmidt, AG., Miller, AD., Baric, RS., Alter, G., Sorger, PK., Estes, JD., Andersen, H., Lewis, MG., ve Barouch, DH. (2020). Sars-cov-2 infection protects against rechallenge in rhesus macaques. Science.

Chatfield, K, Morton, D. (2017). Ethics dumping-the use of non-human primates in research: Springer International Publishing.

Cheng, VC., Lau, SK., Woo, PC., ve Yuen, KY. (2007). Severe acute respiratory syndrome coronavirus as an agent of emerging and reemerging infection. Clin Microbiol Rev, 20(4), 660-694.

Chu, YK., Ali, GD., Jia, F., Li, Q., Kelvin, D., Couch, RC., Harrod, KS., Hutt, JA., Cameron, C., Weiss, SR., ve Jonsson, CB. (2008). The sars-cov ferret model in an infection-challenge study. Virology, 374(1), 151-163.

Cleary, SJ., Pitchford, SC., Amison, RT., Carrington, R., Robaina Cabrera, CL., Magnen, M., Looney, MR., Gray, E., ve Page, CP. (2020). Animal models of mechanisms of sars-cov-2 infection and covid-19 pathology. Br J Pharmacol.

Darnell, ME., Plant, EP., Watanabe, H., Byrum, R., St Claire, M., Ward, JM., ve Taylor, DR. (2007). Severe acute respiratory syndrome coronavirus infection in vaccinated ferrets. $\mathbf{J}$ Infect Dis, 196(9), 1329-1338.

Deng, W., Bao, L., Liu, J., Xiao, C., Liu, J., Xue, J., Lv, Q., Qi, F., Gao, H., Yu, P., Xu, Y., Qu, Y., Li, F., Xiang, Z., Yu, H., Gong, S., Liu, M., Wang, G., Wang, S., Song, Z., Liu, Y., Zhao, W., Han, Y., Zhao, L., Liu, X., Wei, Q., ve Qin, C. (2020). Primary exposure to sarscov-2 protects against reinfection in rhesus macaques. Science.

Dong, BQ., Liu, W., Fan, XH., Vijaykrishna, D., Tang, XC., Gao, F., Li, LF., Li, GJ., Zhang, JX., Yang, LQ., Poon, LL., Zhang, SY., Peiris, JS., Smith, GJ., Chen, H., ve Guan, Y. (2007). Detection of a novel and highly divergent coronavirus from asian leopard cats and chinese ferret badgers in southern china. J Virol, 81(13), 6920-6926.

Gao, Q., Bao, L., Mao, H., Wang, L., Xu, K., Yang, M., Li, Y., Zhu, L., Wang, N., Lv, Z., Gao, H., Ge, X., Kan, B., Hu, Y., Liu, J., Cai, F., Jiang, D., Yin, Y., Qin, C., Li, J., Gong, X., Lou, X., Shi, W., Wu, D., Zhang, H., Zhu, L., Deng, W., Li, Y., Lu, J., Li, C., Wang, X., Yin, W., Zhang, Y., ve Qin, C. (2020). Development of an inactivated vaccine candidate for sars-cov-2. Science, 369(6499), 77-81.

Gillim-Ross, L., Taylor, J., Scholl, DR., Ridenour, J., Masters, PS., ve Wentworth, DE. (2004). Discovery of novel human and animal cells infected by the severe acute respiratory syndrome coronavirus by replication-specific multiplex reverse transcription-pcr. J Clin Microbiol, 42(7), 3196-3206.

Gregory, AC., Zayed, AA., Conceicao-Neto, N., Temperton, B., Bolduc, B., Alberti, A., Ardyna, M., Arkhipova, K., Carmichael, M., Cruaud, C., Dimier, C., Dominguez-Huerta, G., Ferland, J., Kandels, S., Liu, Y., Marec, C., Pesant, S., Picheral, M., Pisarev, S., Poulain, J., Tremblay, JE., Vik, D., Tara Oceans, C., Babin, M., Bowler, C., Culley, AI., De Vargas, C., Dutilh, BE., Iudicone, D., Karp-Boss, L., Roux, S., Sunagawa, S., Wincker, P., ve Sullivan, MB. (2019). Marine DNA viral macro- and microdiversity from pole to pole. Cell, 177(5), 1109-1123 e1114.

Hachim, MY., Al Heialy, S., Hachim, IY., Halwani, R., Senok, AC., Maghazachi, AA., ve Hamid, Q. (2020). Interferon-induced transmembrane protein (ifitm3) is upregulated explicitly in sars-cov-2 infected lung epithelial cells. Front Immunol, 11, 1372.

Halfmann, PJ., Hatta, M., Chiba, S., Maemura, T., Fan, S., Takeda, M., Kinoshita, N., Hattori, SI., Sakai-Tagawa, Y., Iwatsuki-Horimoto, K., Imai, M., ve Kawaoka, Y. (2020). Transmission of sars-cov-2 in domestic cats. N Engl J Med.

Hernandez, M., Abad, D., Eiros, JM., ve RodriguezLazaro, D. (2020). Are animals a neglected transmission route of sars-cov-2? Pathogens, $9(6)$.

Hossain, MG., Javed, A., Akter, S., ve Saha, S. (2020). Sars-cov-2 host diversity: An update of natural infections and experimental evidence. J Microbiol Immunol Infect.

Johnson, CK., Hitchens, PL., Pandit, PS., Rushmore, J., Evans, TS., Young, CCW., ve Doyle, MM. (2020). Global shifts in mammalian population trends reveal key predictors of virus spillover risk. Proc Biol Sci, 287(1924), 20192736.

Kim, YI., Kim, SG., Kim, SM., Kim, EH., Park, SJ., Yu, KM., Chang, JH., Kim, EJ., Lee, S., Casel, MaB., Um, J., Song, MS., Jeong, HW., Lai, VD., Kim, Y., Chin, BS., Park, JS., Chung, KH., Foo, SS., Poo, H., Mo, IP., Lee, OJ., Webby, RJ., Jung, JU., ve Choi, YK. (2020). Infection and rapid transmission of 
sars-cov-2 in ferrets. Cell Host Microbe, 27(5), 704-709 e702.

Kobinger, GP., Figueredo, JM., Rowe, T., Zhi, Y., Gao, G., Sanmiguel, JC., Bell, P., Wivel, NA., Zitzow, LA., Flieder, DB., Hogan, RJ., ve Wilson, JM. (2007). Adenovirus-based vaccine prevents pneumonia in ferrets challenged with the sars coronavirus and stimulates robust immune responses in macaques. Vaccine, 25(28), 5220-5231.

Le Bras, A. (2020). Sars-cov-2 causes covid-19-like disease in cynomolgus macaques. Lab Anim (NY), 49(6), 174.

Leroy, EM., Ar Gouilh, M., ve Brugere-Picoux, J. (2020). The risk of sars-cov-2 transmission to pets and other wild and domestic animals strongly mandates a one-health strategy to control the covid-19 pandemic. One Health, 100133.

Luan, J., Lu, Y., Jin, X., ve Zhang, L. (2020). Spike protein recognition of mammalian ace2 predicts the host range and an optimized ace2 for sars-cov-2 infection. Biochem Biophys Res Commun, 526(1), 165-169.

Maron, DF. (2020.) Coronavirus is killing the dutch mink industry. nationalgeographic, Erişim adresi:

[https://www.nationalgeographic.com/anima ls/2020/06/covid19-forces-mink-farm-endnetherlands/], Erişim tarihi: 13.07.2020.

Menachery, VD., Graham, RL., ve Baric, RS. (2017). Jumping species-a mechanism for coronavirus persistence and survival. Curr Opin Virol, 23, 1-7.

Menachery, VD., Yount, BL, Jr.., Debbink, K., Agnihothram, S., Gralinski, LE., Plante, JA., Graham, RL., Scobey, T., Ge, XY., Donaldson, EF., Randell, SH., Lanzavecchia, A., Marasco, WA., Shi, ZL., ve Baric, RS. (2015). A sars-like cluster of circulating bat coronaviruses shows potential for human emergence. Nat Med, 21(12), 1508-1513.

Menachery, VD., Yount, BL, Jr.., Sims, AC., Debbink, K., Agnihothram, SS., Gralinski, LE., Graham, RL., Scobey, T., Plante, JA., Royal, SR., Swanstrom, J., Sheahan, TP., Pickles, RJ., Corti, D., Randell, SH., Lanzavecchia, A., Marasco, WA., ve Baric, RS. (2016). Sars-like wivl-cov poised for human emergence. Proc Natl Acad Sci U S A, 113(11), 3048-3053.

Mossel, EC., Huang, C., Narayanan, K., Makino, S., Tesh, RB., ve Peters, CJ. (2005). Exogenous ace 2 expression allows refractory cell lines to support severe acute respiratory syndrome coronavirus replication. J Virol, 79(6), 38463850 .

Newman, A., Smith, D., Ghai, RR., Wallace, RM., Torchetti, MK., Loiacono, C., Murrell, LS., Carpenter, A., Moroff, S., Rooney, JA., ve Barton Behravesh, C. (2020). First reported cases of sars-cov-2 infection in companion animals - new york, march-april 2020. MMWR Morb Mortal Wkly Rep, 69(23), 710-713.

Oreshkova, N., Molenaar, RJ., Vreman, S., Harders, F., Oude Munnink, BB., Hakze-Van Der Honing, RW., Gerhards, N., Tolsma, P., Bouwstra, R., Sikkema, RS., Tacken, MG., De Rooij, MM., Weesendorp, E., Engelsma, MY., Bruschke, CJ., Smit, LA., Koopmans, M., Van Der Poel, WH., ve Stegeman, A. (2020). Sars-cov-2 infection in farmed minks, the netherlands, april and may 2020. Euro Surveill, 25(23).

Park, SJ., Yu, KM., Kim, YI., Kim, SM., Kim, EH., Kim, SG., Kim, EJ., Casel, MaB., Rollon, R., Jang, SG., Lee, MH., Chang, JH., Song, MS., Jeong, HW., Choi, Y., Chen, W., Shin, WJ., Jung, JU., ve Choi, YK. (2020). Antiviral efficacies of fda-approved drugs against sarscov-2 infection in ferrets. mBio, 11(3).

Questions and answers on covid-19. (2020.) OIE, Erişim adresi:

https://www.oie.int/scientific-

expertise/specific-information-andrecommendations/questions-and-answerson-2019novel-coronavirus/], Erişim tarihi: 13.07.2020.

Riggioni, C., Comberiati, P., Giovannini, M., Agache, I., Akdis, M., Alves-Correia, M., Anto, JM., Arcolaci, A., Kursat Azkur, A., Azkur, D., Beken, B., Boccabella, C., Bousquet, J., Breiteneder, H., Carvalho, D., De Las Vecillas, L., Diamant, Z., EguiluzGracia, I., Eiwegger, T., Eyerich, S., Fokkens, W., Gao, YD., Hannachi, F., Johnston, SL., Jutel, M., Karavelia, A., Klimek, L., Moya, B., Nadeau, K., O'hehir, R., O'mahony, L., Pfaar, O., Sanak, M., Schwarze, J., Sokolowska, M., Torres, MJ., Van De Veen, W., Van Zelm, MC., Wang, Y., Zhang, L., Jimenez-Saiz, R., ve Akdis, CA. (2020). A compendium answering 150 questions on covid-19 and sars-cov-2. Allergy.

Rockx, B., Kuiken, T., Herfst, S., Bestebroer, T., Lamers, MM., Oude Munnink, BB., De Meulder, D., Van Amerongen, G., Van Den Brand, J., Okba, NMA., Schipper, D., Van Run, P., Leijten, L., Sikkema, R., Verschoor, 
E., Verstrepen, B., Bogers, W., Langermans, J., Drosten, C., Fentener Van Vlissingen, M., Fouchier, R., De Swart, R., Koopmans, M., ve Haagmans, BL. (2020). Comparative pathogenesis of covid-19, mers, and sars in a nonhuman primate model. Science, 368(6494), 1012-1015.

Rosenke, K., Jarvis, MA., Feldmann, F., Schwarz, B., Okumura, A., Lovaglio, J., Saturday, G., Hanley, PW., Meade-White, K., Williamson, BN., Hansen, F., Perez-Perez, L., Leventhal, S., Tang-Huau, TL., Nason, M., Callison, J., Haddock, E., Scott, D., Sewell, G., Bosio, CM., Hawman, D., De Wit, E., ve Feldmann, H. (2020). Hydroxychloroquine proves ineffective in hamsters and macaques infected with sars-cov-2. bioRxiv.

Ruh, E. (2010). [recent developments in sars vaccine studies]. Mikrobiyol Bul, 44(3), 505-517.

See, RH., Petric, M., Lawrence, DJ., Mok, CPY., Rowe, T., Zitzow, LA., Karunakaran, KP., Voss, TG., Brunham, RC., Gauldie, J., Finlay, BB., ve Roper, RL. (2008). Severe acute respiratory syndrome vaccine efficacy in ferrets: Whole killed virus and adenovirusvectored vaccines. J Gen Virol, 89(Pt 9), 2136-2146.

Shan, C., Yao, YF., Yang, XL., Zhou, YW., Gao, G., Peng, Y., Yang, L., Hu, X., Xiong, J., Jiang, RD., Zhang, HJ., Gao, XX., Peng, C., Min, J., Chen, Y., Si, HR., Wu, J., Zhou, P., Wang, YY., Wei, HP., Pang, W., Hu, ZF., Lv, LB., Zheng, YT., Shi, ZL., ve Yuan, ZM. (2020). Infection with novel coronavirus (sars-cov-2) causes pneumonia in rhesus macaques. Cell Res.

Shi, J., Wen, Z., Zhong, G., Yang, H., Wang, C., Huang, B., Liu, R., He, X., Shuai, L., Sun, Z., Zhao, Y., Liu, P., Liang, L., Cui, P., Wang, J., Zhang, X., Guan, Y., Tan, W., Wu, G., Chen, H., ve Bu, Z. (2020). Susceptibility of ferrets, cats, dogs, and other domesticated animals to sars-coronavirus 2. Science, 368(6494), 1016-1020.

Sit, THC., Brackman, CJ., Ip, SM., Tam, KWS., Law, PYT., To, EMW., Yu, VYT., Sims, LD., Tsang, DNC., Chu, DKW., Perera, R., Poon, LLM., ve Peiris, M. (2020). Infection of dogs with sars-cov-2. Nature.

Van Doremalen, N., Lambe, T., Spencer, A., BelijRammerstorfer, S., Purushotham, JN., Port, JR., Avanzato, V., Bushmaker, T., Flaxman, A., Ulaszewska, M., Feldmann, F., Allen, ER., Sharpe, H., Schulz, J., Holbrook, M., Okumura, A., Meade-White, K., Perez-Perez, L., Bissett, C., Gilbride, C., Williamson, BN., Rosenke, R., Long, D., Ishwarbhai, A.,
Kailath, R., Rose, L., Morris, S., Powers, C., Lovaglio, J., Hanley, PW., Scott, D., Saturday, G., De Wit, E., Gilbert, SC., ve Munster, VJ. (2020). Chadox1 ncov-19 vaccination prevents sars-cov-2 pneumonia in rhesus macaques. bioRxiv.

Williamson, BN., Feldmann, F., Schwarz, B., Meade-White, K., Porter, DP., Schulz, J., Van Doremalen, N., Leighton, I., Yinda, CK., Perez-Perez, L., Okumura, A., Lovaglio, J., Hanley, PW., Saturday, G., Bosio, CM., Anzick, S., Barbian, K., Cihlar, T., Martens, C., Scott, DP., Munster, VJ., ve De Wit, E. (2020). Clinical benefit of remdesivir in rhesus macaques infected with sars-cov-2. Nature.

Yu, J., Tostanoski, LH., Peter, L., Mercado, NB., Mcmahan, K., Mahrokhian, SH., Nkolola, JP., Liu, J., Li, Z., Chandrashekar, A., Martinez, DR., Loos, C., Atyeo, C., Fischinger, S., Burke, JS., Slein, MD., Chen, Y., Zuiani, A., Fj, NL., Travers, M., Habibi, S., Pessaint, L., Van Ry, A., Blade, K., Brown, R., Cook, A., Finneyfrock, B., Dodson, A., Teow, E., Velasco, J., Zahn, R., Wegmann, F., Bondzie, EA., Dagotto, G., Gebre, MS., He, X., Jacob-Dolan, C., Kirilova, M., Kordana, N., Lin, Z., Maxfield, LF., Nampanya, F., Nityanandam, R., Ventura, JD., Wan, H., Cai, Y., Chen, B., Schmidt, AG., Wesemann, DR., Baric, RS., Alter, G., Andersen, H., Lewis, MG., ve Barouch, DH. (2020a). DNA vaccine protection against sars-cov-2 in rhesus macaques. Science.

Yu, P., Qi, F., Xu, Y., Li, F., Liu, P., Liu, J., Bao, L., Deng, W., Gao, H., Xiang, Z., Xiao, C., Lv, Q., Gong, S., Liu, J., Song, Z., Qu, Y., Xue, J., Wei, Q., Liu, M., Wang, G., Wang, S., Yu, H., Liu, X., Huang, B., Wang, W., Zhao, L., Wang, H., Ye, F., Zhou, W., Zhen, W., Han, J., Wu, G., Jin, Q., Wang, J., Tan, W., ve Qin, C. (2020b). Age-related rhesus macaque models of covid-19. Animal Model Exp Med, 3(1), 93-97.

Zamoto, A., Taguchi, F., Fukushi, S., Morikawa, S., ve Yamada, YK. (2006). Identification of ferret ace 2 and its receptor function for sarscoronavirus. Adv Exp Med Biol, 581, 519522.

Zhai, X., Sun, J., Yan, Z., Zhang, J., Zhao, J., Zhao, Z., Gao, Q., He, WT., Veit, M., ve Su, S. (2020). Comparison of sars-cov-2 spike protein binding to ace 2 receptors from human, pets, farm animals, and putative intermediate hosts. J Virol. 
Zhang, Q, Zhang, H., Huang, K., Yang, Y., Hui, X., Gao, J., He, X., Li, C., Gong, W., Zhang, Y.,Peng, C., Gao X., Chen H., Zou, Z., Shi, Z., Jin, M. (2020). Sars-cov-2 neutralizing serum antibodies in cats: A serological investigation.
Zhang, T., Wu, Q., ve Zhang, Z. (2020). Probable pangolin origin of sars-cov-2 associated with the covid-19 outbreak. Curr Biol, 30(7), 1346-1351 e1342. 